\title{
Experimental Chronic Chagas' Disease Myocarditis is an Autoimmune Disease Preventable by Induction of Immunological Tolerance to Myocardial Antigens
}

\author{
Lain Pontes-de-Carvalho ${ }^{1,2}$, Cláudia C. Santana1, Milena B. P. Soares ${ }^{1}$, \\ Geraldo G. S. Oliveira ${ }^{1}$, Edecio Cunha-Neto ${ }^{3}$, Ricardo Ribeiro-dos-Santos ${ }^{1,2}$
}

${ }^{1}$ Centro de Pesquisas Gonçalo Moniz, Fundação Oswaldo Cruz, Salvador,

Brazil

${ }^{2}$ Escola Baiana de Medicina e Saúde Pública, Salvador, Brazil

${ }^{3}$ Heart Institute (InCor) and Division of Clinical Immunology and Allergy,

Department of Medicine, University of

São Paulo Medical School, São Paulo,

Brazil

Received 25 October 2001

Accepted 15 December 2001

Key words: anti-CD4, experimental autoimmune

myocarditis, Chagas' disease,

immunological tolerance,

Trypanosoma cruzi

\begin{abstract}
The protozoan Trypanosoma cruzi causes chronic Chagas' disease myocarditis (CCDM) in infected mammals. The pathogenesis of CCDM, however, is still unclear. Indirect evidence for either parasite- or heart-specific immune responses playing a pathogenic role is available. In this work, the participation of autoimmunity in the development of CCDM is demonstrated in mice in which immunological tolerance to heart antigens was induced or strengthened prior to their infection by $T$. cruzi. Tolerance was induced by heart antigen administration in the presence of complete Freund's adjuvant and anti-CD4 antibodies. Tolerized mice developed less intense CCDM than control nontolerized animals that had received only anti-CD4 and adjuvant. This result confirms the important notion that tolerance to self, and in particular to heart antigens, may be reinforced/induced in normal animals, and raises the possibility that analogous interventions may prevent the development of CCDM in millions of T. cruzi-infected human beings.
\end{abstract}

(c) 2002 Elsevier Science Ltd

\section{Introduction}

The protozoan Trypanosoma cruzi infects more than 16 million people in Latin America [1], where it causes Chagas' $^{\prime}$ disease or American trypanosomiasis, a debilitating and often incurable clinical condition [2]. After an acute phase with high parasitism, the parasite may remain quiescent, as far as virulence is concerned, for months or decades, having apparently reached equilibrium with its host [3]. This situation changes in approximately one third of infected individuals, in whom a chronic cardiopathy progressively develops [2], eventually leading to heart failure and death [4]. A main feature of the cardiopathy is chronic Chagas' disease myocarditis (CCDM), which consists of foci of inflammatory mononuclear cells, myocytolysis and interstitial fibrosis, frequently in tissue areas lacking parasites [4].

The major mechanism responsible for the pathogenesis of CCDM is still unknown, in spite of the near one century that has elapsed since the discovery of

Correspondence to: Lain Pontes de Carvalho, Centro de Pesquisas Gonçalo Moniz, FIOCRUZ, Rua Waldemar Falcão 121, 41295-001 Salvador, Brasil. Tel: 55713568781 Ext. 216. Fax: 55713562255. E-mail: lain@cpunet.com.br
Chagas' disease and its etiologic agent [2]. That it has an immunological basis has been undoubtedly established by experiments in athymic nude mice, in which infection by $T$. cruzi causes strikingly high tissue parasitism with very little heart damage [5]. The specificity of the pathogenic immune response, however, is an issue that motivates a great deal of controversy [6-11], as there is no conclusive evidence for its being targeted either to heart or to parasites. The paucity of parasites in CCDM lesions, together with the identification of cardiac myosin-reactive $\mathrm{CD}^{+}{ }^{+} \mathrm{T}$ cells [12] and antibodies [13] in chronically T. cruziinfected mice, as well as the presence of cardiac myosin-specific, $T$. cruzi cross-reactive $\mathrm{CD}^{+}{ }^{+} \mathrm{T}$ lymphocytes and mononuclear cells producing IFN- $\gamma$ and TNF- $\alpha$ infiltrating the heart of CCDM patients [14], are consistent with a pathogenic role for cell-mediated heart antigen-specific autoimmunity. This has been recently substantiated in our laboratories, where an autoreactive $\mathrm{CD}^{+}{ }^{+} \mathrm{T}$-cell line, obtained from chronically $T$. cruzi-infected mice, induced heart lesions in the absence of $T$. cruzi [15]. The effective participation of these autoreactive $\mathrm{T}$ lymphocytes [12, 14, 15] in CCDM development, however, would depend both on the extent of their local representation in the myocardium and on their intrinsic pathogenicity: 
autoimmune phenomena could be an innocuous consequence, rather than a cause, of tissue lesions.

Perhaps the ideal approach to determine the pathogenicity of a given phenomenon is to investigate the development of disease after specifically curbing the phenomenon. This approach has been applied, as described below, to assess the pathogenicity of the immune response against a myosin-rich heart tissue antigenic fraction (myosin-rich Ag) in T. cruzi-infected animals. Mice that were rendered immunologically tolerant or partially tolerant to the experimental induction of autoimmunity against that antigenic fraction, by means of its concomitant administration with anti-CD4 antibodies [16, 17], were subsequently infected with T. cruzi and assessed for the development of CCDM. These mice developed less intense CCDM than control infected mice.

\section{Material and Methods}

\section{Mice and parasites}

Six- to 8-week-old female BALB/c mice, all specificpathogen-free, were raised and maintained at animal facilities in the Gonçalo Moniz Research Centre, Oswaldo Cruz Foundation, Bahia, and provided with rodent diet and water ad libitum. All animals were sacrificed under complete anaesthesia and treated in accordance with the Oswaldo Cruz Foundation Commission for Experiments in Laboratory Animals. Colombian-strain [18] T. cruzi trypomastigotes were obtained from infected LLC-MK ${ }_{2}$ cells (American Type Cell Culture, Rockville, MD), and epimastigotes from axenic cultures in liver infusion-tryptose medium [19].

\section{Antigens}

A cardiac myosin-rich fraction was purified from outbred mouse heart ventricles as previously described [20]. The composition of the preparation was determined by $12 \%$-polyacrylamide gel electrophoresis in the presence of sodium dodecyl sulphate. T. cruzi antigen was prepared from epimastigotes by subjecting them to five freezing and thawing cycles, followed by centrifugation at $30,000 \mathrm{~g}$ for $30 \mathrm{~min}$; supernatants were then aliquoted and stored at $-70^{\circ} \mathrm{C}$ until use.

\section{Induction of autoimmune myocarditis and of immunological tolerance}

Autoimmune myocarditis was induced by the subcutaneous injection of $250 \mu \mathrm{g}$ of myosin-rich $\mathrm{Ag}$, emulsified in complete Freund's adjuvant (CFA; Sigma Chemical Co., St Louis) on days 0 and 7. The degree of heart inflammation and fibrosis was assessed as described below 2 weeks after the last injection.
Immunological tolerance was induced by the administration of the YTS 177.9 non-depleting rat anti-mouse CD4 monoclonal antibody. The monoclonal antibody was kindly supplied by Dr A. Cooke (Department of Pathology, University of Cambridge), and was originally from Dr H. Waldmann. This protocol has been shown to induce immunological tolerance in many systems [16, 17]. Briefly, mice were given one injection of $1 \mathrm{mg}$ of anti-CD4 daily, for three consecutive days, intravenously on the first and intraperitoneally on the two remaining days. On the second day, cardiac myosin-rich Ag was also injected subcutaneously, emulsified in CFA as for induction of autoimmune myocarditis. This procedure was repeated 1 week later. Anti-CD4-treated control mice were injected on the second day with a CFA emulsion without myosin-rich Ag. The anti-CD4 preparation used in this work induced immunological tolerance to human IgG in BALB/c mice, using the same protocol as described above for myosin-rich Ag, but without CFA (not shown).

\section{Experimental T. cruzi infection}

Mice were infected by an intraperitoneal injection of 100 Colombian-strain T. cruzi trypomastigotes. Groups of mice were sacrificed 8 months after infection.

\section{Histopathological studies}

Hearts were removed and fixed in buffered $10 \%$ formalin. Sections were analyzed by optical microscopy after paraffin embedding and standard hematoxylin/eosin staining. Heart tissue-infiltrating inflammatory cells were counted by means of digital morphometry. Briefly, images were digitalized by a JVC TK-1280 color video camera, adapted to an Axioskop 2 microscope (Carl Zeiss, Göttingen, Germany). Inflammatory cells were counted and integrated using the AxioVision II program (Carl Zeiss). The degree of fibrosis was scored on a semiquantitative scale from 0 (absent) to 5 (severe), without previous knowledge of heart identification, in sections stained with Masson's trichrome stain. A total of 10 fields per section were counted, in five sections per heart.

\section{Antibody detection}

Sera were tested for IgG, IgG1 and IgG2a antibodies, against myosin-rich Ag extract or T. cruzi antigen, by ELISA, as described elsewhere [5]. Briefly, microtiter plates were coated with $20 \mu \mathrm{g} \cdot \mathrm{ml}^{-1}$ of mouse myosin-rich heart extract or T. cruzi antigen in $0.05 \mathrm{M}$ carbonate-bicarbonate buffer, $\mathrm{pH} 9.6$, blocked with irrelevant protein, and incubated with a 1:100 dilution of experimental and control sera, followed by biotinylated anti-mouse IgG1, IgG2a and IgG antibodies (Pharmingen) and an extraAvidin-peroxidase 


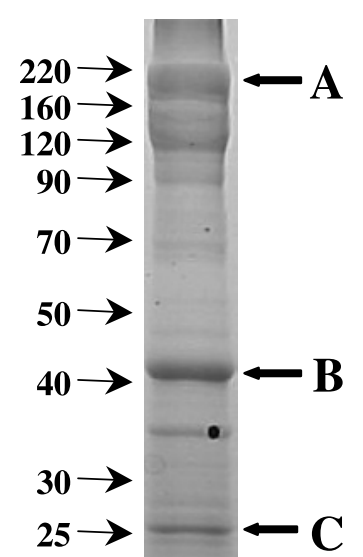

Figure 1. Apparent molecular weights of protein components of the myosin-rich heart antigenic fraction used to induce immunological tolerance. The antigenic fraction was subjected to polyacrylamide gel electrophoresis in the presence of sodium dodecyl sulphate. The proteins were stained with Coomassie blue. Numbers and arrows on the left indicate the position of molecular weight standards. Arrows and letters $\mathrm{A}, \mathrm{B}$ and $\mathrm{C}$ on the right indicate bands with apparent molecular eights corresponding to heart myosin, actin and myosin light chain 1 , respectively.

conjugate (Sigma Chemical Co., St. Louis, USA). Reaction was developed using $\mathrm{H}_{2} \mathrm{O}_{2}$ and 3,3', 5,5'-tetramethylbenzidine (Kinkergaard \& Perry Laboratories, Gaithersburg, MD, USA).

\section{Results}

\section{Partial characterization of myosin-rich heart antigenic fraction}

The composition of the myosin-rich Ag that was used in the immunization and tolerogenic protocols, as analyzed by polyacrilamide gel electrophoresis under reducing conditions, is shown in Figure 1. A major band in the region corresponding to the expected myosin migration position, and at least ten other bands, with molecular weights ranging from 25 to $160 \mathrm{kDa}$, can be seen.

\section{Injection of myosin-rich heart antigenic fraction in the presence of anti-CD4 antibodies induces partial immunological tolerance}

Mice that received myosin-rich $\mathrm{Ag}$ in the presence of anti-CD4 antibodies were resistant to subsequent induction of experimental autoallergic myocarditis, as assessed by quantification of heart inflammatory cells and degree of fibrosis $(P<0.01$, Wilcoxon's rank sum test; Figure 2A and 2B; Figure 3A and 3B). No statistically significant differences $(P>0.05$, Wilcoxon's rank sum test) in levels of antibodies to myosin-rich $\mathrm{Ag}$ between tolerized and control animals were observed (Figure 4A).

\section{Antibodies to T. cruzi and to cardiac myosin in heart antigen-tolerized, T. cruzi-infected mice}

Mice infected with T. cruzi, tolerized or not to cardiac myosin-rich $\mathrm{Ag}$, had very little myosin rich Ag-specific antibodies, both of IgG1 and of IgG2a subclasses, 8 months after infection (Figure 4B). These mice produced similar amounts of IgG1, IgG2a and IgG anti-T. cruzi antibodies (Figure 4B).

\section{Mice tolerant to myosin-rich heart antigens have reduced heart inflammation and fibrosis after T. cruzi infection}

Mice to which myosin-rich Ag was given in a tolerogenic form previous to infection by T. cruzi developed less intense heart inflammation, as assessed by quantification of heart inflammatory cells, than control mice (injected with anti-CD4 antibodies and CFA in the absence of myosin-rich heart antigen) $(P<0.01$, Wilcoxon's rank sum test; Figures 2C and 3C and 3D). The amount of fibrosis in tolerized mice was also lower than in control mice $(P<0.01$, Wilcoxon's rank sum test; Figure 2D).

\section{Discussion}

Although it is unanimously accepted that a delayed type reactivity-like immune reaction is directly responsible for the development of CCDM, there is a great deal of controversy about its specificity [6-11]. Some authors are adamant on the sole relevance of parasite-specific immune responses [9, 11]. In support of their view, it can be pointed out that in all cases of CCDM, T. cruzi antigens and/or parasites are present in affected hearts [21-23], where they would stimulate and target putative parasite-specific pathogenic immune reactions. Moreover, in some murine models of CCDM, syngeneic heart grafts were rejected when transplanted to mice in the acute phase of $T$. cruzi infection [11], presumably after their being infected by parasites circulating in high numbers in the host. In the chronic phase, when heart inflammation is maximal and parasites are rare, there was no rejection of syngeneic heart grafts [11]. The arguments in favor of an autoimmune basis of CCDM, however, are compelling, although not conclusive. In a murine model of CCDM utilizing low numbers of infective Colombian strain trypomastigotes, as would happen in natural infection, syngeneic hearts transplanted in the chronic phase of the infection were rejected [7], without detection of parasite DNA in these hearts by a sensitive PCR (Ribeiro dos Santos et al., unpublished data). Indirect evidence that an anti-T. cruzi immune response by itself does not induce significant tissue damage also comes from the finding of very little or no inflammation in $T$. cruzi-infected tissues other than the heart [24, 25]. Moreover, infection of mice by a non-virulent $T$. cruzi strain that induces no myocarditis by itself renders their heart susceptible to 


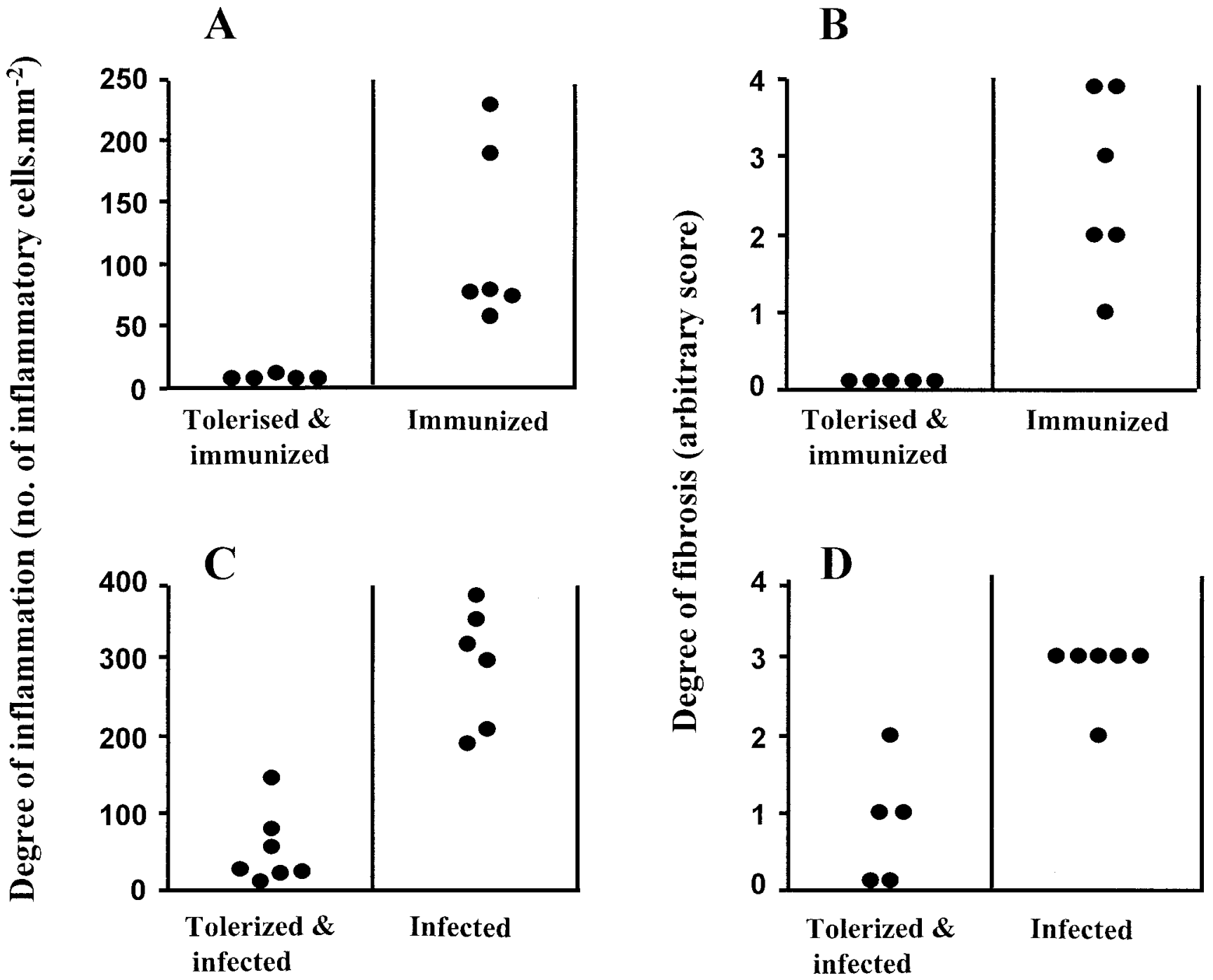

Figure 2. Myocarditis and fibrosis in heart antigen-tolerized and control mice, subsequently immunized with heart antigens (A and B) or infected by T. cruzi (C and D). Data were from 21 days after immunization and from eight months after infection. All represented data were from mice injected with anti-CD4 and complete Freund's adjuvant (CFA). Tolerized mice (Tolerized \& immunized or Tolerized \& infected) additionally received myosin-rich heart antigen, in contrast with control mice (Immunized, or Infected), which were injected only with anti-CD4 and an emulsion of saline and CFA. Inflammatory cells (A and C) were counted in digitalized images, and the degree of fibrosis (B and D) arbitrarily scored, as detailed in Material and Methods section. Symbols correspond to results obtained from individual mice.

autoimmune attack arising from an existing immune response (which had been previously elicited by immunization with heart antigens) (Soares et al., unpublished data), indicating that the heart-specific, pathogenic $\mathrm{T}$ lymphocytes found in the spleen of $T$. cruzi-infected mice [15] have access to heart tissue in the infected mice.

In contrast to the data mentioned above, the results described herein constitute more direct evidence for a pathogenic role of heart-specific autoimmune phenomena in CCDM. They were obtained by comparing two groups of mice that differed only in terms of being injected or not with heart antigens (they both received anti-CD4 antibodies and an adjuvant containing Mycobacterium tuberculosis lysate-the CFA). The heart antigen injections markedly reduced CCDM, clearly associating its development to those antigens.
The finding of normal Th1 and Th2 responses to T. cruzi in tolerized animals, as assessed by determination of antibody isotypes, is consistent with both the specificity of the tolerogenic protocol [16], and its failure to cause a general skewing effect on the Th1/ Th2 cytokine balance. The induction of tolerance, on the other hand, was not complete. Both tolerized and control T. cruzi-infected animals produced similar low levels of anti-myosin-rich Ag antibodies, inclusive of the Th1-dependent IgG2a isotype. As these animals markedly differ in terms of their heart pathology, the present results indicate that the generation of tissue lesions may be under more stringent control than the formation of autoantibodies, and favors the view of the existence of local control of autoimmunity.

The data described herein may close an ongoing controversy [6-11] on the pathogenic relevance of 

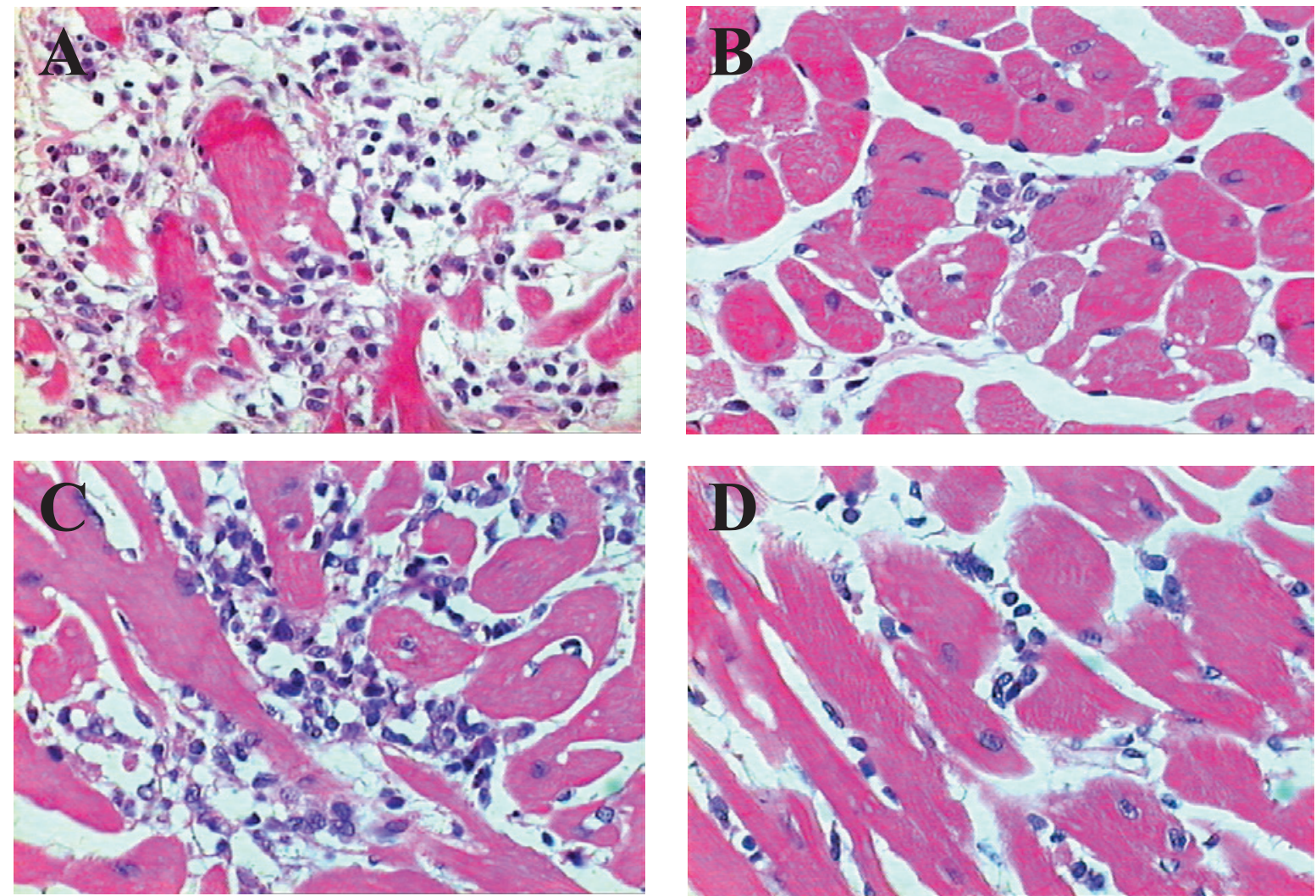

Figure 3. Heart sections of control or heart antigen-tolerized BALB/c mice, subsequently immunized with heart antigens or infected by Trypanosoma cruzi. Control mice, as tolerized mice, were injected with anti-CD4 and complete Freund's adjuvant, but did not receive myosin-rich heart antigen. A, Intense carditis in a control, non-tolerized mouse, three weeks after immunization with myosin-enriched antigen $(H \& E, 200 \times)$. Note the massive destruction of cardiac cells, infiltration by mononuclear cells and interstitial fibrosis. B, Discrete mononuclear cell infiltration within a largely normal myocardium, from a heart antigen-tolerized mouse, three weeks after immunization with heart antigen (H\&E, 400×). C, Myocarditis in a control, non-tolerized mice, 8 months after T. cruzi infection $(H \& E, 400 \times)$. Note the inflammatory infiltration with mononuclear cells frequently juxtaposed to myofibers undergoing cytolysis. D, Discrete myocarditis in heart antigen-tolerized mouse, eight months after T. cruzi infection (H\&E, 400×).

heart-specific autoimmunity in a well-studied and accurate experimental model for human CCDM [5, 7, 15]. The precise heart antigen targeted by the pathogenic autoimmune response, however, has still to be determined, since the antigenic fraction utilized in this work, although enriched for myosin, contains other heart antigens. Myosin seems to be a major autoantigen in the heart: it is the target antigen in Coxsackie B3 virus-induced autoimmune myocarditis [26]; autoantibodies to it are found in normal human beings [6]; myosin-reactive lymphocytes can be detected in T. cruzi-infected mice with myocarditis but not in T. cruzi-infected mice without myocarditis [27]; cardiac myosin-reactive T-cell clones can be isolated from human CCDM lesions [14] and cardiac myosincrossreactive $\mathrm{T}$ cell clones can be derived from T-cell lines specific to a T. cruzi antigen (the B13 protein) [28]. Whether heart myosin is also the target autoantigen in T. cruzi-induced autoimmune cardiomyopathy is amenable to investigation by the approach described herein, provided that recombinant heart myosin or heart myosin purified to homogeneity are used in the tolerogenic protocol.

The mechanism by which tolerance is broken in $T$. cruzi-infected animals also remains to be determined.
Several reports describe cross-reactivities between $T$. cruzi and heart antigens [6, 10, 12, 28], including cardiac myosin $[6,12,28]$, and these could participate in the process of tolerance loss. On the other hand, autoimmunity may well derive from chronic alteration of heart antigens and/or of heart microenvironment by parasite-induced inflammation. The two possibilities, of course, are not mutually exclusive, and in both cases the continuous presence of the parasite could be required for the maintenance of autoimmunity.

Disease control by induction of tolerance to autoantigens, as reported herein for CCDM, has also been reported for non-infectious experimental autoimmune diseases, as for instance experimental autoimmune encephalitis [29] and experimental autoimmune myocarditis [30, 31] (Figure 2a), and for the spontaneous autoimmune diabetes of NOD mice [32]. All these experiments support the important notion that selftolerance can be induced/strengthened by immune intervention.

Although immunological tolerance seems to be easier to induce in naïve than in previously primed individuals, it can be induced in the latter [32, 33]. Lymphocytes from T. cruzi-infected individuals, 


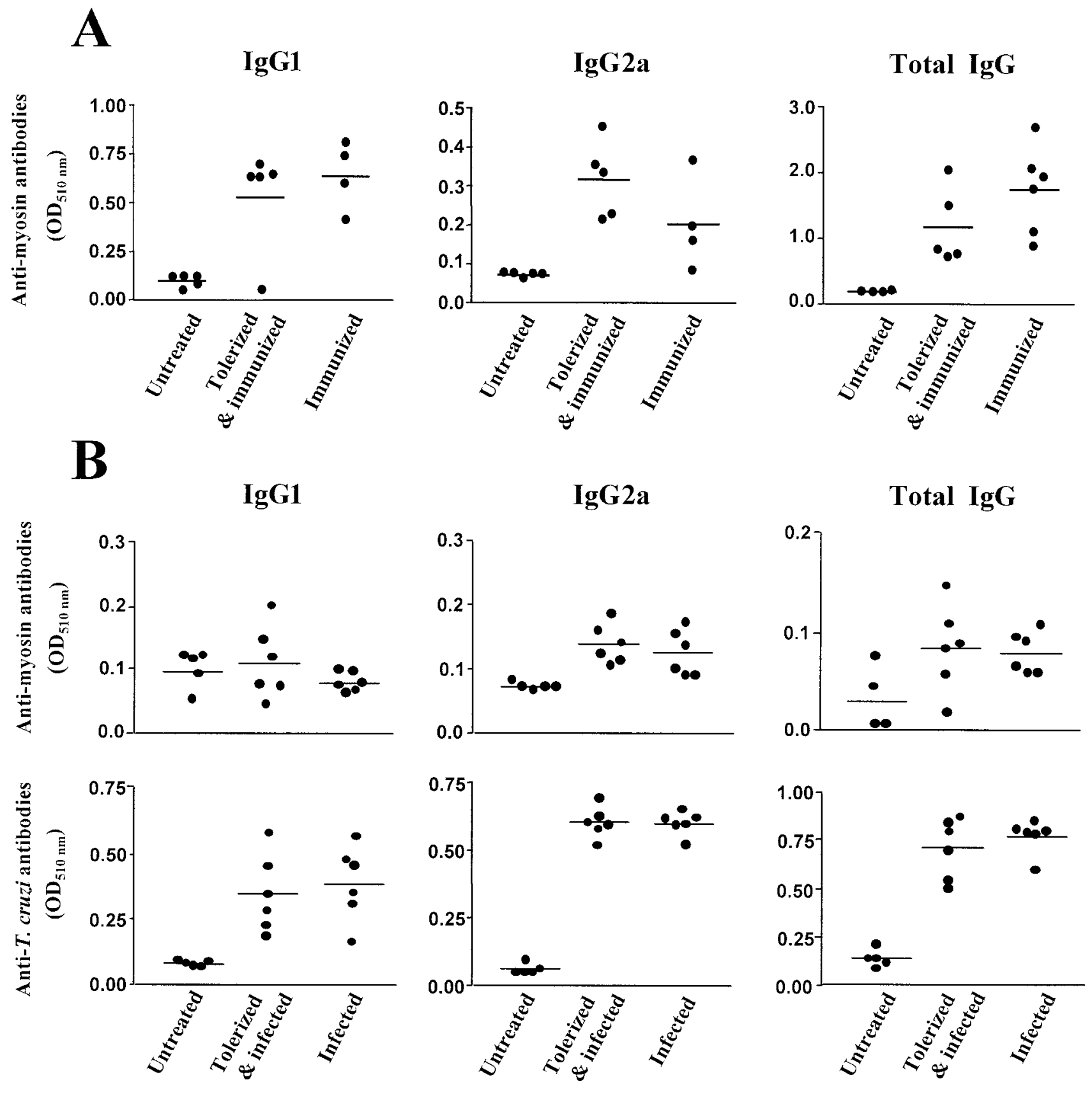

Figure 4. Anti-myosin-rich heart antigen and anti-T. cruzi antibodies in sera from heart antigen-tolerized mice. Tolerized and control mice were either challenged by immunization with heart antigens (A) or infected with T. cruzi (B), as described in Material and methods section. Symbols correspond to results in optical densities $\left(\mathrm{OD}_{510 \mathrm{~nm}}\right)$, obtained from individual mice in an ELISA, for antibodies of the indicated isotypes. Control immunized and infected mice were injected with anti-CD4 and complete Freund's adjuvant, but, contrasting with tolerized mice, did not receive myosin-rich heart antigen. Horizontal bars correspond to mean values of results obtained from five or six animals.

before the establishment of myocarditis, may well be naïve in terms of sensitization to cardiac antigen epitopes that participate in the pathogeny [6]. This also applies for the lymphocytes of the animals used in the present work. The present results suggest the possibility that manipulation of the immune response to heart antigens may be clinically beneficial. This, of course, would ideally be achieved by less aggressive means than anti-CD4 treatment [29-31, 34]. The finding that reinforcement or induction of selftolerance may curb the development of spontaneous autoimmune diseases, as shown herein for CCDM and elsewhere for autoimmune diabetes in NOD mice [32, 35], may therefore have important implications for prevention of autoimmune diseases in individuals in whom a high disease risk can be ascertained by the presence of chronic infection or susceptibilityassociated epidemiological or genetic markers. 


\section{Acknowledgements}

We are thankful to Dr A. Cooke for kindly supplying anti-murine CD4 monoclonal antibodies. This work was supported by UNDP/World Bank/WHO-TDR and by the Conselho Nacional de Desenvolvimento Científico e Tecnológico-CNPq (Brazil).

\section{References}

1. World Health Organization. 1991. Control of Chagas' disease. W.H.O. Tech. Rep. Ser. 811

2. Dias J.C.P., Coura J. 1997. Clínica e terapêutica da doença de Chagas: uma abordagem prática para o clínico geral. FIOCRUZ, Rio de Janeiro, p. 486.

3. Andrade Z.A. 1999. Immunopathology of Chagas disease. Mem. Inst. Oswaldo Cruz. 94(Suppl. 1): 71-80

4. Köberle F. 1968. Chagas' disease and Chagas' syndromes: the pathology of American Trypanosomiasis. Adv. Parasitol. 6: 63-116

5. Soares M.B., Silva-Mota K.N., Lima R.S., Bellintani M.C., Pontes-de-Carvalho L., Ribeiro-dos-Santos R. 2001. Modulation of chagasic cardiomyopathy by interleukin-4: dissociation between inflammation and tissue parasitism. Am. J. Pathol. 159: 703-709

6. Cunha-Neto E., Duranti M., Gruber A., Zingales B., De Messias I., Stolf N., Bellotti G., Patarroyo M.E., Pilleggi F., Kalil J. 1995. Autoimmunity in Chagas disease cardiopathy: biological relevance of a cardiac myosin-specific epitope crossreactive to an immunodominant Trypanosoma cruzi antigen. Proc. Natl. Acad. Sci. USA 92: 3541-3545

7. Ribeiro dos Santos R., Rossi M.A., Laus J.L., Silva J.S., Savino W., Mengel J. 1992. Anti-CD4 abrogates rejection and reestablishes long-term tolerance to syngeneic newborn hearts grafted in mice chronically infected with Trypanosoma cruzi. J. Exp. Med. 175: 29-39

8. Leon J.S., Engman D.M. 2001. Autoimmunity in Chagas heart disease. Int. J. Parasitol. 31: 555-561

9. Tarleton R.L. 2001. Parasite persistence in the aetiology of Chagas disease. Int. J. Parasitol. 31: 550-554

10. Kierszenbaum F. 1999. Chagas' disease and the autoimmunity hypothesis. Clin. Microbiol. Rev. 12: 210-223

11. Tarleton R.L., Zhang L., Downs M.O. 1997. 'Autoimmune rejection' of neonatal heart transplants in experimental Chagas disease is a parasite-specific response to infected host tissue. Proc. Natl. Acad. Sci. USA 94: 3932-3937

12. Rizzo L.V., Cunha-Neto E., Teixeira A.R. 1989. Autoimmunity in Chagas' disease: specific inhibition of reactivity of CD4+ T cells against myosin in mice chronically infected with Trypanosoma cruzi. Infect. Immun. 57: 2640-2644

13. Tibbetts R.S., McCormick T.S., Rowland E.C., Miller S.D., Engman D.M. 1994. Cardiac antigen-specific autoantibody production is associated with cardiomyopathy in Trypanosoma cruzi-infected mice. J. Immunol. 152: 1493-1499

14. Cunha-Neto E., Coelho V., Guilherme L., Fiorelli A., Stolf N., Kalil J. 1996. Autoimmunity in Chagas' disease. Identification of cardiac myosin-B13 Trypanosoma cruzi protein crossreactive T cell clones in heart lesions of a chronic Chagas' cardiomyopathy patient. J. Clin. Invest. 98: 1709-1712
15. Ribeiro-Dos-Santos R., Mengel J.O., Postol E., Soares R.A., Ferreira-Fernandez E., Soares M.B., Pontes-De-Carvalho L.C. 2001. A heart-specific CD4+ T-cell line obtained from a chronic chagasic mouse induces carditis in heart-immunized mice and rejection of normal heart transplants in the absence of Trypanosoma cruzi. Parasite Immunol. 23: 93-101

16. Qin S.X., Wise M., Cobbold S.P., Leong L., Kong Y.C., Parnes J.R., Waldmann H. 1990. Induction of tolerance in peripheral T cells with monoclonal antibodies. Eur. J. Immunol. 20: 2737-2745

17. Hutchings P., O'Reilly L., Parish N.M., Waldmann H., Cooke A. 1992. The use of a non-depleting anti-CD4 monoclonal antibody to re-establish tolerance to beta cells in NOD mice. Eur. J. Immunol. 22: 1913-1918

18. Federici E.E., Albbermann W.N., Neva F.A. 1964. Chronic and progressive myocarditis in $\mathrm{C} 3 \mathrm{H}$ mice infected with Trypanosoma cruzi. Am. J. Trop. Med. Hyg. 13: $272-280$

19. Camargo E.P. 1964. Growth and differentiation of Trypanosoma cruzi. Origin of metacyclic trypanosomes in liquid media. Rev. Inst. Med. Trop. Sao Paulo 6: 93-100

20. Margossian S.S., Lowey S. 1982. Preparation of myosin and its subfragments from rabbit skeletal muscle. Meth. Enzymol. 85: 55-71

21. Olivares-Villagomez D., McCurley T.L., Vnencak-Jones C.L., Correa-Oliveira R., Colley D.G., Carter C.E. 1998. Polymerase chain reaction amplification of three different Trypanosoma cruzi DNA sequences from human chagasic cardiac tissue. Am. J. Trop. Med. Hyg. 59: $563-570$

22. Palomino S.A., Aiello V.D., Higuchi M.L. 2000. Systematic mapping of hearts from chronic chagasic patients: the association between the occurrence of histopathological lesions and Trypanosoma cruzi antigens. Ann. Trop. Med. Parasitol. 94: 571-579

23. Andrade S.G., Pimentel A.R., de Souza M.M., Andrade Z.A. 2000. Interstitial dendritic cells of the heart harbor Trypanosoma cruzi antigens in experimentally infected dogs: importance for the pathogenesis of chagasic myocarditis. Am. J. Trop. Med. Hyg. 63: 64-70

24. Barbosa A.A. Jr, Andrade Z.A. 1984. Identificação do Trypanosoma cruzi nos tecidos extracardíacos de portadores de miocardite crônica chagásica. Rev. Soc. Bras. Med. Trop. 17: 123-126

25. Buckner F.S., Wilson A.J., Van Voorhis W.C. 1999. Detection of live Trypanosoma cruzi in tissues of infected mice by using histochemical stain for beta-galactosidase. Infect. Immun. 67: 403-409

26. Rose N.R., Hill S.L. 1996. The pathogenesis of postinfectious myocarditis. Clin. Immunol. Immunopathol. 80: S92-S99

27. Leon J.S., Godsel L.M., Wang K., Engman D.M. 2001. Cardiac myosin autoimmunity in acute Chagas' heart disease. Infect. Immun. 69: 5643-5649

28. Abel L.C.J., Kalil J., Cunha-Neto E. 1997. Molecular mimicry between cardiac myosin and Trypanosoma cruzi antigen B13: identification of a B13-driven human $\mathrm{T}$ cell clone that recognizes cardiac myosin. Braz. J. Med. Biol. Res. 30: 1305-1308

29. Ben-Nun A., Wekerle H., Cohen I.R. 1981. Vaccination against autoimmune encephalomyelitis with T-lymphocyte line cells reactive against myelin basic protein. Nature 292: 60-61 
30. Wang Y., Afanasyeva M., Hill S.L., Kaya Z., Rose N.R. 2000. Nasal administration of cardiac myosin suppresses autoimmune myocarditis in mice. J. Am. Coll. Cardiol. 36: 1992-1999

31. Godsel L.M., Wang K., Schodin B.A., Leon J.S., Miller S.D., Engman D.M. 2001. Prevention of autoimmune myocarditis through the induction of antigen-specific peripheral immune tolerance. Circulation 103: 1709-1714

32. Phillips J.M., Harach S.Z., Parish N.M., Fehervari Z., Haskins K., Cooke A. 2000. Nondepleting anti-CD4 has an immediate action on diabetogenic effector cells, halting their destruction of pancreatic beta cells. J. Immunol. 165: 1949-1955
33. Marshall S.E., Cobbold S.P., Davies J.D., Martin G.M., Phillips J.M., Waldmann H. 1996. Tolerance and suppression in a primed immune system. Transplantation 62: 1614-1621

34. Soares L.R., Orr P.L., Garovoy M.R., Benichou G. 1998. Differential activation of $\mathrm{T}$ cells by natural antigen peptide analogues: influence on autoimmune and alloimmune in vivo T cell responses. J. Immunol. 160: 4768-4775

35. Bot A., Smith D., Bot S., Hughes A., Wolfe T., Wang L., Woods C., von Herrath M. 2001. Plasmid vaccination with insulin $\mathrm{b}$ chain prevents autoimmune diabetes in nonobese diabetic mice. J. Immunol. 167: 2950-2955 